\title{
О РАСПРЕДЕЛЕНИИ ГРАПТОЛИТОВ В ДИКТИОНЕМОВОМ СЛАНЦЕ ЭСТОНИИ И РАЗНОВОЗРАСТНОСТИ ЕГО ФАЦИИ
}

В связи с изучением возможностей комплексного использования осадочных пород нижнеордовикской полезной толщи Управлением геологин СМ ЭССР было проведено детальное исследование вещественного состава и распространения диктионемовых сланцев (Э. Кивимяги). В процессе этой работы из кернов многочисленных скважин собирались такжеорганические остатки, в частности остатки граптолитов, изучавшиеся в. Институте геологии АН ЭССР (Д. Кальо). Кроме материалов, собранных авторами, в целях нашей статьи использованы старые коллекции А. Эпика (к сожалению не всегда достаточно детально датированные) и некоторые образцы, любезно предоставленные нашими коллегами К. Мююрисеппом, С. Мяги, А. Рыымусоксом и Х. Стумбуром, которым авторы выражают свою благодарность.

Диктионемовые сланцы постоянно привлекают внимание геологов(Tammekann, 1924; Мююрисепп, 1960; Бауков, 1968 и др.), но их иссле.ования ограничивались в основном районом глинта. Накопленные новыематериалы позволяют поставить вопрос о детальной стратиграфии этих сланцев, о возрастных соотношениях отложений в разных районах Эстонии и фациальных связях их с оболовыми песчаниками. В данной статье основное внимание уделяется первым двум вопросам.

Диктионемовые сланцы, резко обозначенные между подстилающими их оболовыми песчаниками и перекрывающими их глауконитовыми песчаниками, составляют по К. Мююрисеппу (1960) тюрисалускую пачку: пакерортского горизонта нижнего ордовика. Распространение пачкн

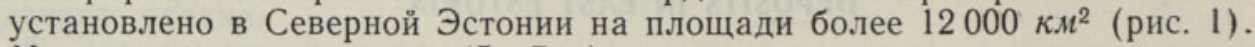
Максимальную мощность $(5-7, \mu)$ пачка имеет в северо-западной части Эстонии, в южном и восточном направлениях она постепенно выклинивается.

Верхняя граница тюрисалуской пачки как с глауконитовыми песчаниками лээтсеского горизонта, так и со сланцеватыми глинами варангуской пачки цератопигевого горизонта (Вийра, Кивимяги, Лоог, 1970) представляет собой отчетливую поверхность перерыва в осадконакоплении. Нижняя граница тюрисалуской пачки также практически везде резкая несмотря на то, что в подстилающих фосфоритоносных оболовых песчаниках и алевролитах маардуской пачки имеются тонкие прослои диктионемового сланца. Только на отдельных участках в приглинтовой. полосе (районы Орасоя и Валкла-Ныммевески) наблюдается переслаивание аргиллитов и алевролитов (так наз. слои типа Орасоя). Поэтому тюрисалуская пачка всегда считалась хорошим маркирующим горизонтом, имеющим четкие границы (см. также Лоог. Кивимяги, 1968). 


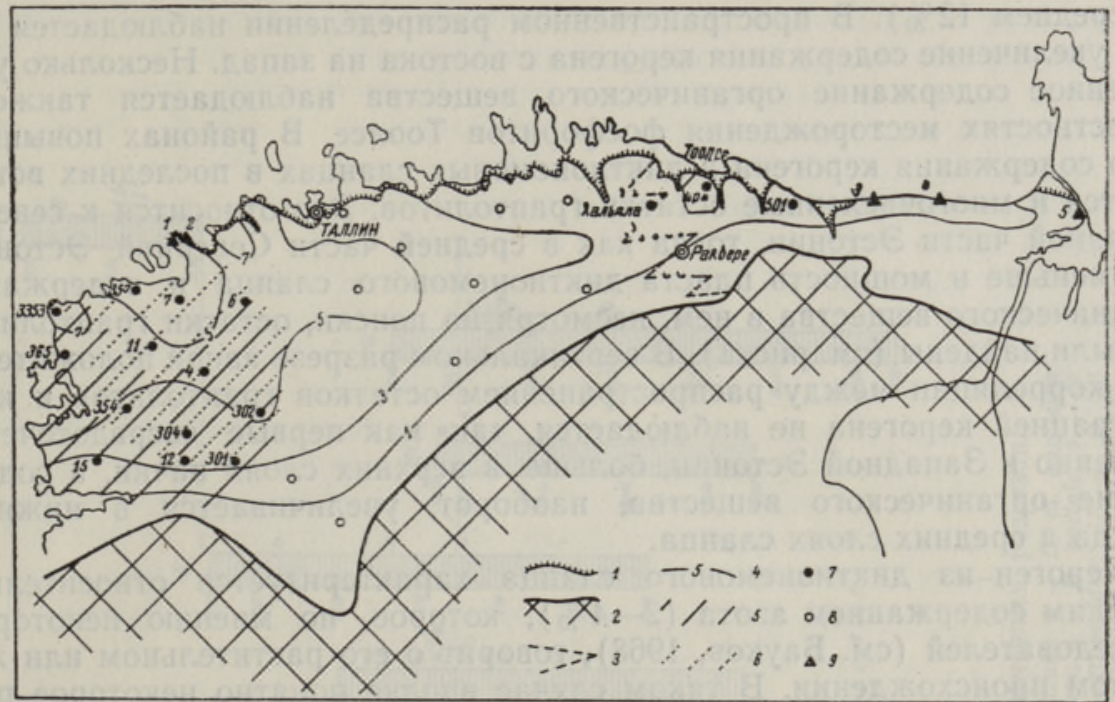

Рнс. 1. Схематическая карта распространения и мощностей аргиллитов тюри салуской пачки.

1 - глинт; 2 - площадь, где тюрисалуская пачка не распространяется: 3 - граница фации: 4 - нзопахиты; 5 - площадь распространення Dictyonema flabelliforme и D. desmogr.zptoides: 6 - площадь распространения $D$. aff. multithecatum; 7 - скважина с на ходками граптолитов: 8 - скважина без находок граптолитов; 9 - обнажения.

Скважины: 4 - Элламаа; 6 - Лайтсе; 7 - Паднзе; 11 - Кунйыэ; 12 - Колувере 15 - Мартна; 301 - Паэкюла: 302 - Ваймыйза; $304-$ Ристи; 354 - Паливере; 354 Вихтерпалу; 365 - Ригульди: $404-$ - Тоотси; 501 - Азери; 3353 - Пыысаспеа.

Обнажения: 1 - Пальдиски (Пакерорт): 2 - Лээтсе; 3 - Сака; 4 - Тойла: 5 - Нарва.

Литологически диктионемовый сланец тюрисалуской пачки представляет собой от светло- до темно-коричневого цвета тонкослоистый аргиллит, содержащий в рассеянном виде органическое вещество (кероген) и некоторые редкие и рассеянные элементы. По гранулометрическому составу аргиллиты в основном состоят из пелитовых частиц; по минералогическому составу в них преобладают глинистые минералы (гидрослюды, каолинит), затем полевые шпаты (в основном ортоклаз), кварц, пирит и органическое вещество; химический состав аргиллитов следующий (в убывающем порядке): $\mathrm{SiO}_{2}, \mathrm{Al}_{2} \mathrm{O}_{3}, \mathrm{~K}_{2} \mathrm{O}, \mathrm{FeS}_{2}$ и C.

Литологический состав тюрисалуской пачки кажется сравнительно однородным, но на самом деле, как было частично известно уже раныше (Tammekann, 1924; Мююрисепп, 1960), наблюдаются заметные различия между аргиллитами в западной и восточной частях Северной Эстонии.

В западной части примерно до линии Хальяла-Раквере (см. рис. 1) распространена сравнительно мощная толща однородных темно-коричневых аргиллитов с тонкими (доли мм) светло-серыми алевритистымн налетами на поверхностях наслоения. Последние и придают аргиллиту сланцеватый облик. Восточнее названной линии распространена менее мощная, но по литологическому характеру более пестрая толща аргиллитов. В последних встречаются тонкие (до 3-4 см) светлые кремнистые (состоящие из спикул кремнистых губок) и сероватые алевритистопесчаные прослойки, а также линзы пирита и конкреции антраконита. Часто встречаются волнистые прослойки, в которых сосредоточены все названные разности пород.

Содержание рассеянного органического вещества в тюрисалуской пачке колеблется в довольно широких пределах - от $3-4$ до $16-17 \%$ 
(в среднем $12 \%$ ). В пространственном распределении наблюдается общее увеличение содержания керогена с востока на запад. Несколько увеличенное содержание органического вещества наблюдается также в окрестностях месторождения фосфоригов Тоолсе. В районах повышенного содержания керогена в диктионемовых сланцах в последних встречаются и многочисленные остатки граптолитов. Это относится к северозападной части Эстонии, тогда как в средней части Северной Эстонии, где меньше и мощность пласта диктионемового сланца и содержание органического вещества в нем, несмотря на поиски, остатки граптолитов не были найдены (см. рис. 1). В вертикальном разрезе явной положительной корреляции между распространением остатков граптолитов и концентрацией керогена не наблюдается, так как первые сосредоточены, особенно в Западной Эстонии, больше в верхних слоях пачки, а содержание органического вещества, наоборот, увеличивается в нижних, иногда в средних слоях сланца.

Кероген из диктионемового сланца характеризуется относительно высоким содержанием азота $(2-4 \%)$, которое, по мнению некоторых исследователей (см. Бауков, 1968), говорит о его растительном или животном происхождении. В таком случае вполне понятно некоторое расхождение максимумов содержания остатков граптолитов и керогена, что вместе с другими литологическими и химическими данными указывает на более сложное, чем принималось обыкновенно, строение тюрисалуской пачки. В стратиграфическом аспекте сказанное получает довольно четкое подтверждение на основе распространения именно остатков граптолитов.

Определимые остатки граптолитов из тюрисалуской пачки собраны из более, чем 20 буровых скважин (рис. 1, 2) и обнаженнй в Пальдиски (мыс Пакерорт), Лээтсе, Сака (?), Тойла и Нарва. По ним в пачке установлены следующие виды или близкие к ним формы граптолитов (номенклатура видов диктионем приводится согласно точке зрения А. Обута, 1953): Dictyonema graptolithinum, D. anglicum, D. sociale, D. multithecatum, D. aff. multithecatum, D. flabelliforme, D. desmograptoides, D. flabelliforme/desmograptoides, Adelograptus cf. hunnebergensis, Clonograptus cf. tenellus, C. cf. callavei, Didymograptus (или Kiaerograptus?) sp.

Учитывая находки остатков граптолитов и в прослоях диктионемового сланца среди оболовых песчаников, а также в варангуских глинах и цератопигевых сланцах, в тремадоке Прибалтики установлена (Кальо, $1971)$ следующая последовательность граптолитовых зон (сверху вниз):

зона Clonograptus tenellus

зона Dictyonema aff. multithecatum

зона D. flabelliforme

зона D. graptolithinum

зона D. sociale

Новый материал позволяет несколько уточнить приведенную схему. Выяснилось, что D. graptolithinum распространен не только в определенной зоне, а почти по всему разрезу диктионемового сланца. Следовательно, этот вид один не может дать детальную стратиграфическую информацию, он может служить только зональным видом зоны D. graptolithinum в широком смысле (т. е. зоны D. flabelififorme в традиционных английских схемах), которой соответствует пакерортский горизонт в целом.

Однако в то же время на основе совокупности видов вышеуказанные зоны выделяются довольно четко: Так, D. sociale приурочен в основном 
$\div$ का शे

mindm

\$ \$ \$

$\therefore \circ$

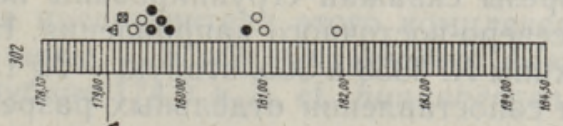

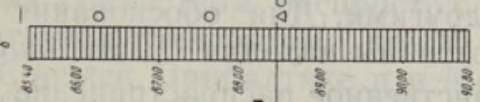

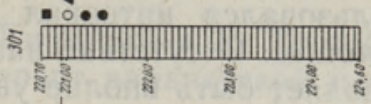

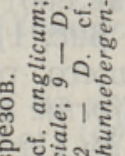

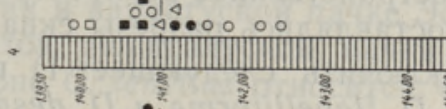

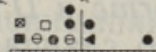

इ

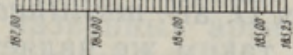

$\approx$

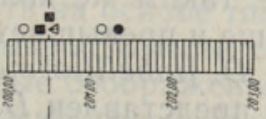

-

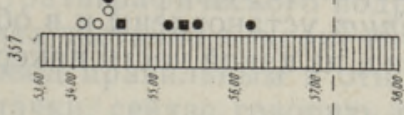

- 1

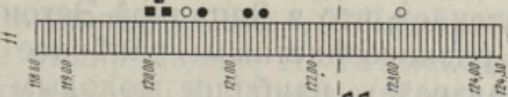

s

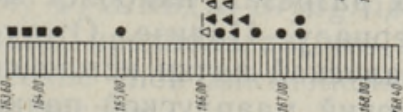

¿

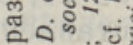

$\times 10$ ํํำ

स- +1 용

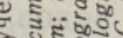

ल क्जि है

- ธูป =

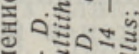

1 1 ह

का 1 के

药1 $=2$.

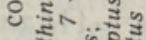

$=$ जิ

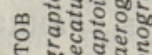

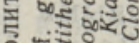

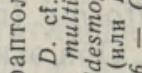

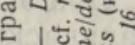

य 205

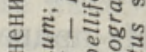

ब.

응

ํㅡㄹ

हुँ

0 콜

ง

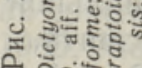

$\therefore$
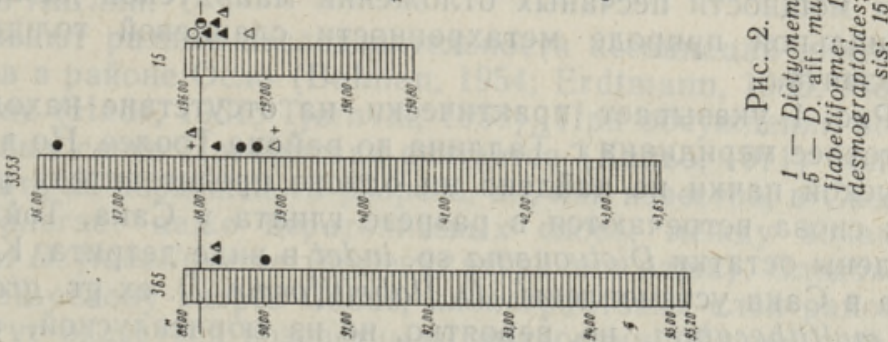
к прослойкам сланца в оболовых песчаниках (в маардуской пачке), D. flabelliforme - только к определенному узкому интервалу, а $D$. aff. multithecatum - к верхам разреза пласта диктионемового сланца, т. е. к верхам тюрисалуской пачки в Северо-Западной Эстонии. Наиболее четко последовательность граптолитовых комплексов прослеживается в: разрезе скв. № 354 (Паливере), являющейся при сопоставлениях опорной.

На рис. 2 разрезы скважин сгруппированы по линиям северного и несколько более северо-восточного направления. Например, одну группу составляют скважины № 3353 и 365 , вторую - № $15 ; 354 ; 11 ; 357 ; 7$ и т. д. (см. рис. 1). При сопоставлении отдельных разрезов в качестве маркирующего горизонта использовался интервал распространения D. flabelliforme и D. desmograptoides. Отсутствие названных видов в скважинах № 11; 357 и 7 не позволяет быть вполне уверенным в правильности сопоставления этих скважин с другими. Для обоснования корреляции последних скважин были использованы находки D. aff. multithecatum.

На рис. 1 показано и пространственное распространение трех названных вндов, по которым сопоставлялись разрезы скважин.

По рисункам можно заключить следующее: 1) в наиболее южных скважинах (№ $15 ; 12 ; 301)$ D. flabelliforme и $D$. desmograptoides встречаются в верхах пласта диктионемового сланца, мощность которого не превышает 4 м. Если встречается $D$. aff. multithecatum, то лишь в самых верхах разреза. 2) В принципе таким же является разрез скв. № 365 , только его мощность здесь больше и превышает 6 м. 3) В районе Вихтерпалу-Падизе (скв. № 357 и 7) D. flabelliforme и D. desmograptoides не установлены, но многочисленно представлен D. aff. multithecatum. Мощность сланца в этом районе обычно меньше 5 . В разрезах между названными районами (скв. № 354; 304; 4 и др.) представлены как $D$. flabelliforme (примерно в средней части разреза), так и $D$. aff. multithecatum. Оба эти вида вместе с D. graptolithinum установлены и в обнажении у Пальдиски, но, к сожалению, не известно, из какой части пакерортского горизонта они происходят.

Из приведенного материала вытекает, что в Западной Эстонии пласт диктионемового сланца является разновозрастным: наиболее древним сланец является в юго-западных разрезах, наиболее молодым - в северо-восточных, в районе Вихтерпалу-Падизе. Отсутствие в последнем самых нижних слоев тюрисалуской пачки компенсируется увеличениєм мощности песчаных отложений маардуской пачки, что говорит о фациальной природе метахронности сланцевой толщи пакерортского горизонта.

Рис. 1 указывает практически на отсутствие находок граптолитов. восточнее меридиана г. Таллина до района Тоолсе. Но в Тоолсе из тюрисалуской пачки не найдено ни одного представителя рода Dictyonema. Они снова встречаются в разрезе глинта у Сака, Тойла и Нарва, где. найдены остатки Dictyonema sp. indet в виде детрита. Кроме такого детрита в Сака установлены $D$. flabelliforme, $D$. ex gr. graptolithinum и $D$. aff. multithecatum, но, вероятно, не из тюрисалуской, а из маардуской пачки. Эти образцы собраны А. Эпиком, который в описании Сакаского. разреза отмечает многочисленные хорошо сохранившиеся остатки: Dictyonema в прослоях диктионемого сланца в оболовых песчаниках.

В районе Тоолсе по 10 скважинам (на рис. 2 из них приведен только разрез скв. № 404) в тюрисалуской пачке, залегающей под варангускими глинами, установлены следующие граптолиты: Clonograptus cf. callavei, C. cf. tenellus, Adelograptus cf. hunnebergensis, A. ? sp., Anisograptus sp., 
Bryograptus sp., Didymograptus (или Kiaerograptus?). Первый вид является наиболее частым, остальные встречаются только отдельными экземплярами. Последний встречен в тюрисалуской пачке и в разрезе скв. Азери (№ 501, на глубине 6,8 м). К сожалению фрагментарность материала не допускает его более точного определения.

Приведенный комплекс граптолитов весьма сходен с ассоциацией зоны C. tenellus и A. hunnebergensis в Швеции и в некоторой мере с ассоциацией цератопигевых слоев в Норвегии (см. Monsen, 1925; Erdtmann, 1965). Отдельные представители этого комплекса найдены в Эстонии и в варангуской пачке - в обн. Сухкрумяги Adelograptus ? sp., в разрезе скв. Арду на глубине 174,0 м A. cf. hunnebergensis и Clonograptus cf. tenellus.

Недавно В. Вийра, Э. Кивимяги и А. Лоог (1970) доказали по конодонтам цератопигевый возраст варангуской пачки, а Д. Кальо (1971), основываясь на совместном распространении C. tenellus с определенными конодонтами и трилобитами, пришел к выводу о соответствии зоны C. tenellus в Средней Прибалтике и в Московской синеклизе цератопигевым слоям Норвегии и варангуской пачке Эстонии.

Состав граптолитов тюрисалуской пачки в районе Тоолсе-Азери показывает, что к зоне C. tenellus относится частично и диктионемовый сланец в традиционном понимании как толща темно-коричневых сланцеватых аргиллитов, залегающих в кровле оболовых песчаников. Полное отсутствие диктионем в названных аргиллитах в районе Тоолсе-Азери указывает на неправильность на основе только литологического сходства называть их «диктионемовыми». Вмесге с тем различие граптолитовых ассоциаций и корреляционные соображения указывают, вероятно, на более молодой возраст тоолсеских клонограптовых сланцев по сравнению с диктионемовыми сланцами в западной фации тюрисалуской пачки. Поскольку и те и другие входят в состав тюрисалуской пачки, как единого литостратиграфического подразделения, то следует констатировать, что эта пачка частично выходит из рамок пакерортского горизонта. Будет ли этот вывод правильным в отношении всей восточной «фации» тюрисалуской пачки, сейчас говорить рано, так как вышеуказанные находки остатков диктионем у Сака и Тойла требуют еще проверки. Здесь уместно отметить и высказывание А. Таммеканна (Tammekann, 1924), который, ссылаясь на находку Ф. Шмидта Bryograptus kjerulfi на берегу р. Пуртсе (западнее обн. Сака), предполагал, что местами могли сохраниться от размыва более высокие слои диктионемовых сланцев, соответствующие зоне Bryograptus в Англии.

Сомнения вызывают разные последовательности ассоциаций диктионем и клонограптов в районе Осло (Bulman, 1954; Erdtmann, 1965; Monsen, 1925) и в Сконе (Hede, 1951; Tjernvik, 1958). При обсуждении возраста клонограптовых слоев Прибалтики считается (Кальо, 1971) более правильным исходить из норвежского разреза, но, как известно, в Сконе зона $C$. tenellus залегает ниже цератопигевых слоев, между зонами D. graptolithinum и D. flabelliforme (номенклатура зон наша). Следовательно, принимая за основу разрез Сконе, клонограптовые слои района Тоолсе-Азери могут оказаться возрастными аналогами (фацией). диктионемовых сланцев Западной Эстонии. Решение этой проблемы, поднимающей и вопрос о фациальной приуроченности диктионем и клонограптов, следует искать в дальнейшем изучении как возрастных соотношений, так и палеогеографической обстановки образования пакерортских отложений. 


\title{
ЛИТЕРАТУРА
}

Б а уко в С. С. 1968. Общая характеристика диктионемовых сланцев. В кн.: Геология месторождений угля и горючих сланцев СССР, 11, M.

В и й р а В., К и в и м я г и Э., Л о ог А. 1970. О литологии и возрасте варангуской пачки (тремадок Северной Эстонии). Изв. АН ЭССР, Хим. Геол., 19, № 2.

Кальо Д. Л. 1971. О граптолитовых зонах тремадока и аренига Прибалтийской и Московской синеклиз. В кн.: Граптолиты СССР. Тр. I коллоквиума граптолитологов СССР, М. (в печати).

Л оог А., К и в и м я г и Э. 1968. Литостратиграфия пакерортского горизонта в Эстонии. Изв. АН ЭССР, Хим. Геол., 17, № 4.

М ю ю и с еп п К. К. 1960. Литостратиграфия пакерортского горизонта в Эстонской ССР по данным обнажений. Тр. Ин-та геол. АН ЭССР, 5.

О бу т А. М. 1953. Дендроидеи Северо-Запада Русской платформы. Тр. ВНИГРИ, нов. cep., 78.

$\mathrm{Bu} 1 \mathrm{~m}$ a n O. M. B. 1954. The graptolite fauna of the Dictyonemà Shales of the Oslo region. Norsk geol. Tidsskr,, 33.

Erdtma nn B.-D. 1965. Eine spät-Tremadocische Graptolithenfauna von Töyen in Oslo. Norsk geol. Tidsskr., 45.

Hede J. E. 1951. Boring through Middle Ordovician-Upper Cambrian Strata in the Fâgelsång District, Scania (Sweden). Lunds Univ. Årsskr. N. F., Avd. 2, 46, Nr. 7.

Monsen A. 1925. Uber eine neue ordovicische Graptolitenfauna. Norsk Geol. Tidsskr., 8.

T a m mekann A. 1924. Eesti diktüoneemakihi uurimine tema tekkimise, vanaduse ja levimise kohta. Acta et commet. Univ. Dorpatensis, ser. A, 5, No. 6.

Tjernvik T. E. 1958. The Tremadocian Beds at Flagabro in South-Eastern Scania (Sweden). Geol. Fören. Stockh. Förhandl., 80.

\author{
Ннститут геологии \\ Академии наук Эстонской ССР \\ Управление геологии \\ Совета Министров Эстонской ССР
}

Поступила в редакцию

24/IV 1970

D. KALJO, E. KIVIMÄGI

\section{GRAPTOLIITIDE LEVIKUST DIKTUONEEMAKILDAS JA SELLE FAATSIESTE ERINEVATEST VANUSTEST EESTIS}

Iseloomustatakse kilda (türisalu kihistu) litoloogilise koostise, eriti orgaanilise aine (kerogeeni) sisalduse ja paksuse muutusi levila eri osades. Järsem muutus esineb umbes Haljala-Rakvere joonel. Graptoliitide esinemise põhjal näidatakse, et türisalu kihistiku vanimad kihid levivad Riguldi-Martna-Koluvere, keskmised Vihterpalu-Padise ümbruses. Toolse-Aseri piirkonna kihid on noorimad ning kuuluvad tōenäoliselt tseratopüüge lademesse.

\section{KALJO, E. KIVIMÄGI}

\section{ON THE DISTRIBUTION OF GRAPTOLITES IN THE DICTYONEMA SHALE OF ESTONIA AND ON THE UNCONTEMPORANEITY OF ITS DIFFERENT FACIES}

Dictyonema shale forms the Türisalu Member of the Pakerort Stage distributed in North Estonia (Fig. 1; legends: 1 - the Glint; 2 - area where the Türisalu Member is missing; 3 - border of the different facies; 4 - isopachites; 5 - distribution area of Dictyonema flabelliforme and $D$. desmograptoides; 6 - distribution area of $D$. aff. multithecatum; 7 - borehole; 8 - borehole in which no graptolites were found; 9 ... outcrop; the names of boreholes and outcrops are presented, according to numbers, in the Russian text). The lithology of the Türisalu Member eastwards of the Haljala-Rakvere line gets increasingly varied: there occur abundant aleuritic and silicous interlaminations and anthraconite and pyrite concretions.

The content of organic matter (kerogen) in argillite increases in the western direction, but its maximum in the vertical sequence does not really coincide with the maximum abundance of graptolites. 
The sections examined have been correlated according to the distribution of graptolites, In the first line, the occurrence of Dictyonema flabelliforme and D. desmograptoides has been considered, which are represented in a narrow part of the sequence (Fig. 2; the graptolites determined are marked by signs, the explanation of which is to be found in the Russian text). It seems that the Türisalu Member consists of beds of different age: the oldest beds are those of the Riguldi-Martna-Koluvere region (Fig. 1, borings Nos $365,15,12)$, the intermediate ones - of the Vihterpalu-Padise region (borings Nos 357,7 ), and the youngest beds of the Tcolse-Aseri region (borings Nos 404, 501). The latter do not contain representatives of Dictyonema and, in consideration of the occurrence of Clonograptus tenellus together with conodonts and trilobites of the Ceratopyge beds in South Latvia, as well as according to the sequence of the Moscow Syneclise (cf. Кальо, 1971), those strata are considered as analogues of the Ceratopyge Series. That conclusion has been reached on the basis of correlation with the Dictyonema shale of Norway (Bulman, 1954). A comparison with the Skone sequence (Hede, 19.31, Tjernvik, 1958), however, leads to another assumption, i. e. that the different facies of the Dictyonema shale of Estonia may be contemporaneous. In the given case the contemporaneity of the facies is considered less probable. 